\title{
Efisiensi Penggunaan Pupuk pada Sistem Pertanian Terpadu Minapadi
}

\author{
Fertilizer Use Efficiency in Integrated Rice-fish Farming System
}

\author{
Tri Astuti ${ }^{1}$, Suwarto $^{2 *}$, Herdhata Agusta $^{2}$, dan Irzal Effendi ${ }^{3}$ \\ ${ }^{1}$ Program Studi Agronomi dan Hortikultura, Sekolah Pascasarjana, Institut Pertanian Bogor \\ ${ }^{2}$ Departemen Agronomi dan Hortikultura, Fakultas Pertanian, Institut Pertanian Bogor \\ (IPB University), Jl. Meranti, Kampus IPB Darmaga, Bogor 16680, Indonesia \\ ${ }^{3}$ Departemen Budidaya Perikanan, Fakultas Perikanan dan Ilmu Kelautan, Institut Pertanian Bogor \\ (IPB University), Jl. Agatis, Kampus IPB Dramaga, Bogor 16680, Indonesia
}

Diterima 10 Maret 2020/Disetujui 24 Juli 2020

\begin{abstract}
Rice-fish farming is a model that is considered suitable to be applied in rice fields, both on a large or limited land as long as water availability is sufficient for growing rice an fish. In rice-fish farming, there is integration between fisheries and agriculture where integration can improve the efficiency of the supply and use of fertilizer and feed. The research aimed to find the reduction of inorganic fertilizer in integrated rice-fish farming with the rice-fish system to increase fertilizer efficiency. The experiment used a single factor randomized block design with five levels of treatment, which are; rice monoculture with $100 \%$ inorganic fertilizer, fish monoculture, rice-fish farming with $100 \%$ inorganic fertilizer, rice-fish farming with $60 \%$ inorganic fertilizer, and rice-fish farming with 20\% inorganic fertilizer. Rice-fish farming could reduce the application of inorganic fertilizers through complementary relationships between rice and fish. Applying inorganic fertilizer $20 \%$ of the reference dose in the rice-fish farming produced productivity that was not significantly different from the rice-fish farming fertilized with $60 \%$ and $100 \%$ of the reference dose, and the rice monoculture with $100 \%$ of the reference dose of inorganic fertilizer. Rice-fish farming could save $80 \%$ of inorganic fertilizers so that increasing the efficiency of using inorganic fertilizers. Fish survival and fish weight in rice-fish farming were not significantly different from fish monoculture.
\end{abstract}

Keywords: inorganic fertilizer, monoculture, productivity, soil nutrients

\section{ABSTRAK}

Minapadi adalah suatu model yang dianggap sesuai untuk diterapkan di sawah, baik pada lahan yang luas ataupun terbatas selama ketersediaan air mencukupi kebutuhan padi dan ikan untuk tumbuh. Pada minapadi terdapat pengintegrasian antara perikanan dan pertanian yang mana pengintegrasian tersebut dapat meningkatkan ketersediaan pupuk dan pakan. Penelitian ini bertujuan untuk mengetahui pengurangan pupuk anorganik pada pertanian terpadu padi-ikan dengan sistem minapadi sehingga dapat meningkatkan efisiensi pemupukan. Rancangan penelitian menggunakan rancangan acak kelompok faktor tunggal dengan lima taraf perlakuan, yaitu: padi monokultur 100\% pupuk anorganik, monokultur ikan, minapadi dengan $100 \%$ pupuk anorganik, minapadi dengan 60\% pupuk anorganik, dan minapadi dengan 20\% pupuk anorganik. Minapadi dapat mengurangi penggunaan pupuk anorganik melalui hubungan komplementer antara padi dan ikan. Pemberian pupuk anorganik $20 \%$ dosis anjuran pada minapadi menghasilkan produktivitas padi tidak berbeda nyata dengan minapadi 60\% dan 100\% dosis anjuran dan dengan padi monokultur 100\% dosis anjuran. Minapadi dapat menghemat $80 \%$ pupuk anorganik sehingga meningkatkan efisiensi penggunaan pupuk anorganik. Kelangsungan hidup ikan dan berat ikan pada minapadi tidak berbeda nyata dengan monokultur ikan.

Kata kunci: monokultur, produktivitas, pupuk anorganik, unsur hara

\section{PENDAHULUAN}

Petanian terpadu (integrated farming) merupakan suatu pendekatan pada pertanian sebagai perbandingan dari pendekatan monokultur yang sudah ada dengan mengacu

* Penulis untuk korespondensi. e-mail: wrtskm@yahoo.com pada sistem pertanian yang mengintegrasikan peternakan konvensional, budidaya perairan, hortikultura, agroindustri dan aktivitas pertanian lainnya dengan mengedepankan keseimbangan dan memperhatikan kesehatan lingkungan serta pengoptimalan aliran energi (Rana dan Chopra, 2013). Pertanian terpadu dianggap dapat meningkatkan kualitas lingkungan karena memiliki tingkat keanekaragaman 
yang lebih tinggi dibandingkan dengan monokultur dan pada gilirannya dapat memberikan dampak positf terhadap lingkungan. Dampak positif tersebut diantaranya menekan laju erosi tanah, meningkatkan karbon organik tanah, meningkatkan fungsi biologis tanah, mengurangi penggunaan air irigasi, dan meningkatkan kualitas air (Sanderson et al., 2013). Pertanian terpadu juga bertujuan untuk meningkatkan hasil serta keuntungan baik sosial ataupun ekonomi. Salah satu bentuk dari sistem ini ialah minapadi. Menurut Cahyaningrum et al. (2014) penerapan sistem minapadi menguntungkan, karena petani dapat memperoleh padi dan juga ikan dalam waktu bersamaan. Minapadi memiliki stabilitas hasil padi yang sama dengan monokultur padi. Hal tersebut dikaitkan dengan adanya interaksi positif antara padi dan ikan yang menghasilkan sifat ekosistem.

Sifat ekosistem yang terjadi pada minapadi diantaranya adalah ikan dapat menjadi biokontrol pada tanaman padi, padi mendapatkan manfaat dari ikan dengan menurunkan serangan hama serangga, penyakit, gulma, serta dapat mengurangi pertumbuhan spora dan miselium yang disebabkan karena tanaman padi terguncang oleh aktivitas ikan dalam air. Manfaat yang didapatkan ikan dari padi diantaranya yaitu, padi menyediakan naungan bagi ikan dan menurunkan suhu air pada siang hari, meningkatkan kelarutan $\mathrm{N}$ dan membantu menurunkan konsentrasi amonia dalam air dan total $\mathrm{N}$ di dalam tanah, sehingga kualitas air lebih baik untuk ikan (Fengbo et al., 2019; Siikavuopio et al., 2012; Xie et al., 2011). Padi juga menyediakan sumber makanan tambahan bagi ikan seperti serangga pemakan daun yang jatuh dari tanaman padi (Hu et al., 2013). Integrasi padi dan ikan ini akan meningkatkan keterkaitan pemanfaatan aliran input-output antar kedua komoditas sehingga proses produksi menjadi lebih efisien. Penelitian ini bertujuan untuk mengetahui pengurangan pupuk anorganik pada pertanian terpadu padi-ikan dengan sistem minapadi sehingga dapat meningkatkan efisiensi pemupukan.

\section{BAHAN DAN METODE}

Penelitian dilaksanakan di Kampung Cisuru, Desa Padajaya, Kecamatan Jampangkulon, Sukabumi, Jawa Barat. Tanah dianalisis di Laboratorium Pengujian, Departemen Agronomi dan Hortikultura, IPB. Air dianalisis di Laboratorium Produktivitas dan Lingkungan Perairan, Departemen Manajemen Sumberdaya Perairan, IPB. Penelitian dilaksanakan pada bulan Desember 2017 sampai Juli 2018.

Kondisi tanah di awal penelitian adalah agak alkalis dengan kapasitas tukar kation (KTK) tinggi, C-organik sedang, $\mathrm{N}$ total sedang, $\mathrm{P}$ dan $\mathrm{K}$ total sangat tinggi. Nilai karakteristik tanah dan statusnya tertera pada Tabel 1. Air di awal penelitian memiliki TDS $188 \mathrm{mg} \mathrm{L}^{-1}$, TSS $<8 \mathrm{mg} \mathrm{L}^{-1}$, EC $408 \mu \mathrm{s} \mathrm{cm}^{-1}, \mathrm{NO}_{2}^{-} 0.01 \mathrm{mg} \mathrm{L}^{-1}, \mathrm{NO}_{3}^{-} 0.31 \mathrm{mg} \mathrm{L}^{-1}, \mathrm{TOM}$ $4.42 \mathrm{mg} \mathrm{L}^{-1}$, dan DO $8.10 \mathrm{mg} \mathrm{L}^{-1}$, yang memenuhi kualitas untuk memelihara ikan.

Penelitian menggunakan rancangan acak kelompok faktor tunggal dengan lima taraf perlakuan dan diulang empat kali sehingga ada 20 unit percobaan. Kelima taraf perlakuan adalah monokultur padi $100 \%$ pupuk anorganik, monokultur ikan, minapadi $100 \%$ pupuk anorganik, minapadi $60 \%$ pupuk anorganik, dan minapadi $20 \%$ pupuk anorganik. Dosis pupuk anorganik sesuai anjuran BB Padi (2015) yaitu $92 \mathrm{~kg} \mathrm{~N}, 36 \mathrm{~kg} \mathrm{P}_{2} \mathrm{O}_{5}$, dan $61 \mathrm{~kg} \mathrm{~K} \mathrm{O}_{2} \mathrm{O}$ per hektar. Tiap unti percobaan berukuran $5 \mathrm{~m} \times 5 \mathrm{~m}$. Padi yang digunakan varietas IPB 3S. Jenis ikan adalah ikan mas.

Unit percobaan monokultur ikan disiapkan berupa kolam dengan kedalaman air $50 \mathrm{~cm}$. Unit percobaan padi monokultur disiapkan petakan sawah dengan ketinggian air dipertahankan $20 \mathrm{~cm}$ di atas permukaan tanah. Pada minapadi setiap unit percobaan di buat parit keliling (kemalir) dengan kedalaman $30 \mathrm{~cm}$ dan air dipertahankan $20 \mathrm{~cm}$ di atas permukaan tanah seperti pada monokultur.

Padi ditanam menggunakan sistem jajar legowo 2:1 dan jarak tanam $50 \mathrm{~cm}$ antar barisan (lorong), $25 \mathrm{~cm}$ dalam baris antar rumpun, dan $12.5 \mathrm{~cm}$ jarak dalam baris (Abdulrachman et al., 2013). Bibit padi ditanam sebanyak 4 bibit per rumpun. Pemupukan padi dengan 100\% dosis

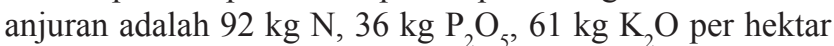
sesuai dosis anjuran BB Padi (2015). Pupuk diaplikasikan pada 14 dan 45 hari setelah tanam (HST), sesuai waktu yang tepat untuk pemberian N, P dan K menurut Buresh (2006). Pemeliharaan pada tanaman padi meliputi penyulaman 1-2 minggu setelah tanam (MST), pengairan dengan menggunakan pengairan berselang dari saat tanam sampai anakan maksimum yaitu tiap 3 hari diairi ketinggian 3 $\mathrm{cm}$ dan 3 hari berikutnya dikeringkan macak-macak, pengendalian gulma, serta hama dan penyakit dilakukan

Tabel 1. Karakteristik kimia tanah dan air pada awal penelitian

\begin{tabular}{lrl}
\hline Karakteristik tanah & Nilai & Status*) \\
\hline $\mathrm{pH} \mathrm{H} \mathrm{H}_{2} \mathrm{O}$ & 8.10 & Agak alkalis \\
$\mathrm{KTK}\left(\mathrm{cmol}(+) \mathrm{kg}^{-1}\right)$ & 31.36 & Tinggi \\
$\mathrm{C}$-organik $(\%)$ & 2.34 & Sedang \\
$\mathrm{N}$ total $(\%)$ & 0.30 & Sedang \\
$\mathrm{P}$ total $\left(\mathrm{mg} \mathrm{P}_{2} \mathrm{O}_{5} / 100 \mathrm{~g}\right)$ & 191.07 & Sangat tinggi \\
$\mathrm{K}$ total $\left({\left.\mathrm{mg} 100 \mathrm{~g}^{-1}\right)}\right.$ & 62.86 & Sangat tinggi \\
\hline
\end{tabular}

Keterangan: *Kriteria menurut Laboratorium Tanah SEAMEO BIOTROP (2018) 
secara mekanik dan kimiawi. Panen padi dilakukan pada saat padi $90 \%$ sudah matang secara fisiologis dengan ditandai menguningnya bulir padi.

Budidaya ikan monokultur di kolam menerapkan prosedur: 3 hari sebelum ikan ditebar, kolam diberi dolomit 3 ton ha-1 $\left(300 \mathrm{~g}\right.$ per $\left.\mathrm{m}^{2}\right)$ dan pupuk kandang ayam 2 ton ha $\mathrm{h}^{-1}$ (200 $\mathrm{g}_{\text {per }} \mathrm{m}^{2}$ ) untuk mempercepat pertumbuhan plankton sebagai pakan alami, selanjutnya ikan ditebar. Pada padi monokultur dan minapadi pupuk tersebut tidak diberikan.

Penebaran ikan pada minapadi dilakukan saat padi bermalai $90 \%$ yaitu pada 10 MST (minggu setelah tanam). Padat penebaran 2 ekor ikan mas per $\mathrm{m}^{2}$ dengan rataan panjang $\pm 7 \mathrm{~cm}$ dan rataan bobot $\pm 7 \mathrm{~g}$ per ekor. Ketinggian air pada monokultur dan minapadi dipertahankan pada ketinggian yang sama yaitu $20 \mathrm{~cm}$ di atas permukaan tanah selama 30 hari pemeliharaan ikan. Pemeliharaan ikan dilakukan selama 30 hari dan disesuaikan dengan umur padi siap panen serta secara berkala diberikan pakan tambahan baik pada monokultur ikan maupun minapadi berupa pelet halus dan dedak dengan dosis 5\% dari bobot biomassa sehingga dibutuhkan pakan sebesar $0.28 \mathrm{~kg}$ per hari. Selama pemeliharaan ikan, pengelolaan air pada petak padi monokultur dan minapadi dilakukan dengan cara yang sama, yaitu mengatur ketinggian air $20 \mathrm{~cm}$ di atas permukaan tanah menggunakan pintu air, sedangkan untuk kolam monokultur pada ketinggian $50 \mathrm{~cm}$. Penanggulangan hama dilakukan dengan cara pemasangan jaring dan pagar bambu, dipancing dengan umpan serta pemberian penerangan di sekeliling area pemeliharaan ikan. Panen ikan pada minapadi dilakukan pada umur 30 hari setelah tebar, sebelum padi dipanen dengan membuang air dari petakan padi di pagi dan sore untuk menghindari ikan stres. Setelah air dibuang ikan terkumpul di kemalir.

Peubah pertumbuhan dan produksi padi yang diamati adalah jumlah anakan pada saat 7 MST (saat anakan maksimum), jumlah anakan produktif, bobot gabah berisi, bobot gabah hampa, presentase gabah hampa, jumlah gabah berisi per rumpun. Pengukuran hasil ubinan dan untuk pendugaan hasil per hektar dilakukan dari ubinan berukuran $2.5 \mathrm{~m} \times 2.5 \mathrm{~m}$ dari tiap perlakuan. Dugaan hasil ubinan dalam peubah gabah kering panen (GKP) dengan kadar air 19\% dan gabah kering giling (GKG) dengan kadar air 13\% dalam satuan hektar. GKP dihitung dengan rumus Purwanto et al. $(2017)$, produktivitas GKP $=$ hasil ubinan $\times\left(\frac{\text { luas } 1 \text { hektar }}{\text { luas ubinan }}\right)$. Selanjutnya produktivitas GKG dihitung dengan rumus $((100-19) /(100-13)) *$ bobot GKP. Peubah pengamatan pada ikan meliputi: kelangsungan hidup ikan (Survival Rate) dengan rumus: $\mathrm{SR}=\frac{\mathrm{Nt}}{\mathrm{No}} \times 100 \%$ (SR: kelangsungan hidup ikan (\%), Nt: jumlah ikan pada akhir penelitian, No: jumlah ikan pada awal penelitian); pertambahan panjang mutlak $(\mathrm{cm})$ dengan rumus: $\mathrm{P}=\mathrm{Pt}-\mathrm{Po}(\mathrm{P}$ : panjang ikan (cm), Pt: panjang ikan pada akhir penelitian, Po: panjang ikan pada awal penelitian); pertumbuhan bobot mutlak (g) dengan rumus: $\mathrm{W}=\mathrm{Wt}-\mathrm{Wo}(\mathrm{W}$ : bobot ikan $(\mathrm{g})$, $\mathrm{Wt}$ : Bobot ikan pada akhir penelitian, Wo: Bobot ikan pada awal penelitian); rasio konversi pakan (Feed Convertion Ratio) dengan rumus: $\mathrm{FCR}=\frac{\mathrm{F}}{(\mathrm{Wt}+\mathrm{D})-\mathrm{W}_{\mathrm{q}}} \quad(\mathrm{FCR}$ : rasio konversi pakan, $\mathrm{F}$ : jumlah pakan yang díberikan $(\mathrm{g})$, Wt: Bobot ikan pada akhir penelitian (g), D: jumlah ikan yang mati selama pemeliharaan (hari), Wo: Jumlah ikan pada awal penelitian). Metode pengukuran pertumbuhan dan perkembangan ikan tersebut mengikuti Effendie (1979).

Analisis usaha tani dilakukan dengan menghitung $\mathrm{B} / \mathrm{C}$ rasio (Benefit Cost Ratio) menggunakan rumus: $\mathrm{B} / \mathrm{C}$ Ratio $=\frac{\text { Benefit }}{\text { Cost }}$. Data hasil pengamatan dianalisis uji $\mathrm{F}$ dengan menggunakan aplikasi SAS 9.4. Apabila terdapat beda nyata, dilanjutkan dengan uji DMRT (Duncan Multiple Range Test) taraf 5\% pada peubah padi dan $10 \%$ peubah ikan.

\section{HASIL DAN PEMBAHASAN}

\section{Pertumbuhan dan Produksi Padi}

Pertumbuhan padi diamati melalui penghitungan jumlah anakan maksimum dan jumlah anakan produktif. Pada saat 7 MST, tanaman padi sistem minapadi yang dipupuk anorganik 100\% dosis acuan menghasilkan anakan maksimum lebih banyak dibandingkan dengan monokultur yang dipupuk anorganik 100\% dosis acuan dan minapadi dengan $60 \%$ dan $20 \%$ dosis acuan (Tabel 2). Pengaruh ikan pada peubah tersebut belum ada karena ikan baru ditebarkan ketika padi berumur 10 MST. Petak sawah untuk minapadi yang sejak awal dipersiapkan dengan saluran keliling (kemalir) memberikan keuntungan berupa kelembaban tanah tetap terjaga secara merata, ketika lahan dikeringkan pada kondisi macak-macak saluran tersebut tetap terisi air dengan ketinggian permukaan tanah. Kemalir keliling dapat berfungsi mengalirkan air irigasi merembes ke lahan sampai macak-macak (Kalsim et al., 2007). Sementara untuk tanah di petak sawah monokultur setelah 3 hari kondisi macakmacak, tanah mengalami retak rambut. Keadaan tanah yang terjaga kelembabannya oleh adanya kemalir diduga menyebabkan pertumbuhan anakan di petak minapadi yang dipupuk $100 \%$ dosis acuan lebih tinggi daripada di petak monokultur dengan dosis yang sama. Hal ini sesuai dengan pernyataan Nurfaijah et al. (2015) bahwa perlakuan irigasi pada rejim agak basah memberikan jumlah anakan padi tertinggi.

Terhadap peubah anakan produktif yang dihitung saat panen, tidak terdapat perbedaan yang nyata antara perlakuan monokultur dengan pupuk anorganik 100\% dosis acuan dan minapadi (dengan pupuk anorganik 20\%, 60\% dan 100\% dosis acuan), dan monokultur dengan 100\% dosis acuan. Keberadaan ikan tidak berpengaruh pada anakan produktif karena penebaran sudah di akhir fase vegetatif tanaman yaitu saat tanaman telah bermalai $90 \%$. Hal yang dinyatakan oleh Lazzari dan Baldisserotto (2008) bahwa hasil buangan ekskresi (feses) merupakan sumber tambahan hara pada tanaman padi berupa amonia dan fosfat, selama pertumbuhan vegetatif tidak terjadi di penelitian ini. Menurut Oehme et al. (2007) adanya penambahan pakan ikan pada minapadi dapat meningkatkan hara tersedia untuk tanaman padi dari sisa pakan, sehingga pada saat dosis pupuk anorganik untuk padi dikurangi dapat ditutupi dari tambahan sisa pakan ikan tersebut, pada penelitian ini hanya terjadi pada fase pengisian dan pemasakan malai. 
Tabel 2. Jumlah anakan dan jumlah anakan produktif padi per rumpun

\begin{tabular}{lcc}
\hline Perlakuan & Jumlah anakan & Jumlah anakan produktif \\
\hline Monokultur padi 100\% pupuk anorganik & $13.2 \mathrm{~b}$ & $8.8 \mathrm{a}$ \\
Monokultur ikan & 0.0 & 0.0 \\
Minapadi 100\% pupuk anorganik & $18.2 \mathrm{a}$ & $7.8 \mathrm{a}$ \\
Minapadi 60\% pupuk anorganik & $14.0 \mathrm{~b}$ & $8.2 \mathrm{a}$ \\
\hline Minapadi 20\% pupuk anorganik & $12.5 \mathrm{~b}$ & 18.02 \\
\hline KK $(\%)$ & 15.42 & \\
\hline
\end{tabular}

Keterangan: Huruf yang sama di belakang angka pada kolom yang sama menunjukkan tidak berbeda nyata berdasarkan uji DMRT pada $\operatorname{taraf} \alpha=5 \%$ KK $=$ koefisien keragaman.

Unsur hara $\mathrm{N}$ sangat penting dalam produksi tanaman karena dapat merangsang pertumbuhan vegetatif, meningkatkan jumlah anakan dan jumlah bulir per rumpun, serta menambah ukuran gabah (Patti et al., 2013; Siregar dan Marzuki, 2011; Tando, 2018). Penyerapan tinggi N pada padi terjadi fase reproduktif dimulai pada saat fase bunting (booting stage), keluar malai dan pengisian biji. Pada fase tersebut tanaman padi banyak menyerap $\mathrm{N}$ untuk pengisian gabah (Patti et al., 2013; Xiang et al., 2013). Apabila terjadi kahat $\mathrm{N}$ dapat menyebabkan tanaman kerdil, sistem perakaran terbatas, daun kekuning-kuningan dan terjadi klorosis di bagian ujungnya, serta mengurangi jumlah anakan, jumlah malai dan jumlah gabah (Abu et al., 2017; Rauf et al., 2000; Senoaji dan Praptana, 2013). Akan tetapi, apabila kelebihan unsur $\mathrm{N}$ akan merusak dan memperlambat tanaman matang, mudah rebah, menurunkan kualitas bulir, menurunkan biomassa tanaman, hasil gabah dan efisiensi penyerapan nitrogen, serta menurunkan daya tahan terhadap hama dan penyakit (Senoaji dan Praptana, 2013; Triadiati et al., 2012). Berbagai pernyataan di atas terlihat pada peubah komponen produksi seperti jumlah dan bobot gabah per rumpun dan produktivitas padi.

Jumlah dan bobot gabah per rumpun baik pada monokultur maupun minapadi secara statistik tidak berbeda nyata. Pada saat pupuk anorganik dikurangi sampai 20\% pada minapadi menghasilkan jumlah dan bobot gabah berisi tidak berbeda nyata dengan monokultur padi $100 \%$ pupuk anorganik (Tabel 3). Hal tersebut diduga karena ikan dapat memanfaatkan $\mathrm{N}$ yang tidak diserap oleh tanaman padi melalui konsumsi produsen primer akuatik. Sebaliknya, hasil metabolisme serta buangan eksresi dari ikan berupa feses dan sisa pakan dapat menjadi pupuk organik yang mengandung $\mathrm{N}$ yang mampu meningkatkan jumlah bulir padi (Patti et al., 2013; Siregar dan Marzuki, 2011; Tando, 2018) dan pengisian biji atau bobot gabah (Patti et al. 2013; Xiang et al., 2013). Penambahan pupuk organik tersebut dapat semakin memperbaiki kondisi lingkungan yang sesuai untuk pertumbuhan padi, hara semakin tersedia untuk diserap akar (Hu et al., 2013; Sudiarta et al., 2016; Xie et al., 2011).

Berdasarkan Tabel 4 terlihat bahwa hasil GKP dan GKG tidak berbeda nyata antara monokultur dan minapadi. Pengurangan pupuk anorganik hingga 20\% pada minapadi menghasilkan produktivitas gabah tidak berbeda nyata dengan monokultur yang dipupuk anorganik 100\%. Hal tersebut menunjukkan bahwa budidaya dengan adanya padi dan ikan memiliki hasil yang tinggi dengan mengoptimalkan manfaat dari sumber daya lahan dan air sebagai interaksi saling melengkapi dan sinergis antara padi dan ikan serta tidak ada penurunan hasil panen padi pada budidaya minapadi (Hu et al., 2013; Hu et al., 2015).

Peningkatan hasil panen padi pada budidaya minapadi erat kaitannya dengan efek positif dari aktivitas langsung dan tidak langsung ikan yang menyebabkan pelepasan nutrien tetap dari tanah ke air dan membuat tanah berpori sehingga nutrien mudah untuk diserap oleh padi dan mengurangi

Tabel 3. Jumlah, presentase, dan bobot gabah per rumpun padi

\begin{tabular}{|c|c|c|c|c|c|}
\hline \multirow{2}{*}{ Perlakuan } & \multicolumn{2}{|c|}{ Jumlah gabah } & \multirow{2}{*}{$\begin{array}{l}\text { Presentase } \\
\text { gabah } \\
\text { hampa }(\%)\end{array}$} & \multicolumn{2}{|c|}{ Bobot gabah (g) } \\
\hline & Berisi & Hampa & & Berisi & Hampa \\
\hline Monokultur padi $100 \%$ pupuk anorganik & $667.8 \mathrm{a}$ & $417.2 \mathrm{a}$ & 39.2 & $22.8 \mathrm{a}$ & $5.8 \mathrm{a}$ \\
\hline Monokultur ikan & 0.0 & 0.0 & 0.0 & 0.0 & 0.0 \\
\hline Minapadi $100 \%$ pupuk anorganik & $830.0 \mathrm{a}$ & $401.5 \mathrm{a}$ & 32.7 & $27.5 \mathrm{a}$ & $5.2 \mathrm{a}$ \\
\hline Minapadi $60 \%$ pupuk anorganik & $765.2 \mathrm{a}$ & $336.8 \mathrm{a}$ & 30.7 & $25.5 \mathrm{a}$ & $5.5 \mathrm{a}$ \\
\hline Minapadi $20 \%$ pupuk anorganik & $692.2 \mathrm{a}$ & $302.8 \mathrm{a}$ & 30.7 & $22.2 \mathrm{a}$ & $3.8 \mathrm{a}$ \\
\hline KK $(\%)$ & 18.01 & 10.36 & 3.91 & 17.84 & 12.45 \\
\hline
\end{tabular}

Keterangan: Huruf yang sama di belakang angka pada kolom yang sama menunjukkan tidak berbeda nyata berdasarkan uji DMRT pada $\operatorname{taraf} \alpha=5 \% ; \mathrm{KK}=$ koefisien keragaman. 
kompetisi nutrien antara tanaman padi dan gulma (Tsuruta et al., 2011; Vromant dan Chau, 2005; Xie et al., 2011). Ikan juga dapat menyebabkan distribusi dan penggunaan nutrisi lebih efisien oleh tanaman padi dengan adanya integrasi padi dan ikan (Noorhosseini-Niyaki dan Bagherzadeh-Lakani, 2013). Berdasarkan nilai berbagai peubah pertumbuhan dan produksi padi (Tabel 2 dan 4) dan berbagai uraian di atas, menunjukkan bahwa penambahan pupuk anorganik pada minapadi sebanyak 20\% dosis acuan pada tanah dengan status nitrogen sedang serta fosfor dan kalium sangat tinggi (Tabel 1) telah cukup untuk mendapatkan hasil yang tidak berbeda dengan dosis yang lebih tinggi (60\% dan 100\% dosis acuan pada minapadi, dan $100 \%$ dosis acuan pada monokultur). Minapadi pada tanah dengan status hara tersebut dapat meningkatkan efisiensi penggunaan pupuk anorganik.

\section{Pertumbuhan dan Kelangsungan Hidup Ikan}

Ikan mas yang ditebar dengan bobot $\pm 7 \mathrm{~g}$ dan panjang $\pm 7 \mathrm{~cm}$ mengalami pertumbuhan seperti tertera pada Tabel 5. Pertambahan bobot ikan mas yang diusahakan secara monokultur tidak berbeda nyata dengan di sistem minapadi dengan berbagai dosis pupuk anorganik, namun di budidaya monokultur ukuran ikan lebih panjang dari minapadi (Tabel 5). Hal tersebut diduga karena ikan pada minapadi memiliki kemampuan dalam memanfaatkan pakan dan tambahan pakan dari luar seperti spora, miselium, dan serangga herbivora (pemakan daun) yang jatuh ke dalam air ( $\mathrm{Hu}$ et al., 2013; Xie et al., 2011), walaupun pada tingkat 20\% dosis acuan pupuk anorganik. Menurut Cahyanti et al. (2014), faktor yang berperan adalah kemampuan ikan beradaptasi terhadap lingkungan baru dan mampu memanfaatkan pakan alami di sawah serta pakan tambahan yang diberikan, sehingga dapat mempengaruhi pertumbuhan ikan yang tidak berbeda dengan monokultur. Ikan yang lebih panjang pada budidaya monokultur dibandingkan dengan yang di minapadi adalah terkait dengan ruang gerak pertumbuhan ikan (Febrianti et al., 2016); pada monokultur ikan lebih leluasa bergerak dibandingkan dengan minapadi yang lebih sempit ruang geraknya, yaitu yang berkedalaman air $50 \mathrm{~cm}$ hanya di kemalir.
Feed conversion ratio (FCR) pada minapadi tidak berbeda nyata dengan monokultur, tetapi nilainya lebih besar dibandingkan monokultur (Tabel 5). Hal tersebut diduga disebabkan oleh pemberian pakan melebihi kapasitas lambung dan terbuang. Menurut Sunarno (1991), jumlah pakan yang sesuai adalah sesuai dengan kapasitas lambung dan kecepatan pengosongan lambung atau saat ikan dalam kondisi lapar dan membutuhkan pakan, pada saat tersebut nafsu makan ikan akan meningkat. Menurut Cahyanti et al. (2014), ikan mas tidak terlalu memanfaatkan pelet serta lebih menyukai lumut dan pakan alami lainnya yang ada di tepian kolam atau sawah. Minapadi dapat menyediakan plankton lebih banyak seperti Chlorella. Faktor yang mempengaruhi pertumbuhan ikan menurut Febrianti et al., (2016) adalah faktor internal (diantaranya adalah umur dan sifat genetik ikan meliputi keturunan, kemampuan dalam memanfaatkan makanan dan ketahanan terhadap penyakit) dan faktor eksternal atau lingkungan (meliputi sifat fisika dan kimia air, ruang gerak dan ketersediaan makanan). FCR yang tinggi pada minapadi, diduga karena lingkungan tumbuh ikan menjadi lebih kondusif karena adanya naungan oleh tanaman padi yang menyebabkan air menjadi lebih sejuk, serangga kecil atau hama yang berjatuhan dari tanaman padi juga dapat dimanfaatkan sebagai pakan oleh ikan.

Berdasarkan hasil pengamatan, ikan mas mampu beradaptasi baik pada budidaya secara monokultur maupun minapadi di lahan sawah dengan berbagai dosis pemupukan anorganik. Hal tersebut ditunjukkan dengan tingkat kelangsungan hidup (SR) selama pemeliharaan 30 hari pada kedua sistem budidaya tersebut lebih besar dari $85 \%$ (Tabel 5). Setiap perlakuan memiliki lingkungan yang sesuai untuk budidaya ikan mas baik monokultur maupun minapadi, karena parameter kualitas air berada pada rentang yang cocok.

\section{Analisis Usaha Tani}

Analisis usaha tani dilakukan untuk mengetahui keuntungan yang didapatkan dari selisih antara total biaya produksi dengan penerimaan usaha tani monokultur dengan minapadi (Tabel 6 dan Tabel 7). Monokultur padi dengan $100 \%$ pupuk anorganik menghasilkan $\mathrm{B} / \mathrm{C}$ ratio 1.2 dan

Tabel 4. Hasil ubinan GKP, hasil ubinan GKG, dugaan hasil GKP, dan dugaan hasil GKG padi

\begin{tabular}{|c|c|c|c|c|}
\hline Perlakuan & $\begin{array}{l}\text { Hasil ubinan GKP } \\
\quad\left(\mathrm{kg} \text { per } 2.5 \mathrm{~m}^{2}\right)\end{array}$ & $\begin{array}{l}\text { Hasil ubinan } \mathrm{GKG} \\
\quad\left(\mathrm{kg} \text { per } 2.5 \mathrm{~m}^{2}\right)\end{array}$ & $\begin{array}{c}\text { Dugaan hasil } \\
\text { GKP } \\
\left(\text { ton } \text { ha }^{-1}\right)\end{array}$ & $\begin{array}{c}\text { Dugaan hasil } \\
\text { GKG } \\
\left(\text { ton } \mathrm{ha}^{-1}\right)\end{array}$ \\
\hline Monokultur padi $100 \%$ pupuk anorganik & $3.47 \mathrm{a}$ & $2.93 \mathrm{a}$ & $5.55 \mathrm{a}$ & $5.12 \mathrm{a}$ \\
\hline Monokultur ikan & 0.00 & 0.00 & 0.00 & 0.00 \\
\hline Minapadi $100 \%$ pupuk anorganik & $3.81 \mathrm{a}$ & $3.26 \mathrm{a}$ & $6.10 \mathrm{a}$ & $5.67 \mathrm{a}$ \\
\hline Minapadi $60 \%$ pupuk anorganik & $3.30 \mathrm{a}$ & $2.95 \mathrm{a}$ & $5.28 \mathrm{a}$ & $4.88 \mathrm{a}$ \\
\hline Minapadi $20 \%$ pupuk anorganik & $3.40 \mathrm{a}$ & $2.82 \mathrm{a}$ & $5.44 \mathrm{a}$ & $5.01 \mathrm{a}$ \\
\hline KK $(\%)$ & 12.86 & 12.12 & 12.86 & 12.52 \\
\hline
\end{tabular}

Keterangan: Huruf yang sama di belakang angka pada kolom yang sama menunjukkan tidak berbeda nyata berdasarkan uji DMRT pada $\operatorname{taraf} \alpha=5 \%$. GKP $=$ Gabah kering panen; GKG $=$ Gabah kering giling 
Tabel 5. Rataan pertambahan panjang, bobot mutlak, SR, FCR dan produksi ikan dengan pemeliharaan selama 30 hari

\begin{tabular}{|c|c|c|c|c|c|}
\hline Perlakuan & $\begin{array}{c}\text { Bobot } \\
\text { mutlak } \\
\text { (g per ekor) }\end{array}$ & $\begin{array}{c}\text { Pertambahan } \\
\text { panjang } \\
(\mathrm{cm})\end{array}$ & SR $(\%)$ & FCR & $\begin{array}{l}\text { Produksi } \\
\text { ikan } \\
\left(\text { ton } \text { ha }^{-1}\right)\end{array}$ \\
\hline Monokultur padi $100 \%$ pupuk anorganik & 0.0 & 0.0 & 0.0 & 0.0 & 0.0 \\
\hline Monokultur ikan & $25.9 \mathrm{a}$ & $5.0 \mathrm{a}$ & $85.0 \mathrm{a}$ & $2.1 \mathrm{a}$ & $0.52 \mathrm{a}$ \\
\hline Minapadi $100 \%$ pupuk anorganik & $19.8 \mathrm{a}$ & $4.6 \mathrm{ab}$ & $89.5 \mathrm{a}$ & $3.6 \mathrm{a}$ & $0.46 \mathrm{a}$ \\
\hline Minapadi $60 \%$ pupuk anorganik & $19.6 \mathrm{a}$ & $3.6 \mathrm{ab}$ & $89.5 \mathrm{a}$ & $4.1 \mathrm{a}$ & $0.48 \mathrm{a}$ \\
\hline Minapadi $20 \%$ pupuk anorganik & $15.8 \mathrm{a}$ & $2.8 \mathrm{~b}$ & $91.0 \mathrm{a}$ & $5.5 \mathrm{a}$ & $0.41 \mathrm{a}$ \\
\hline KK (\%) & 15.43 & 12.40 & 12.75 & 13.48 & 6.48 \\
\hline
\end{tabular}

Keterangan: Huruf yang sama di belakang angka pada kolom yang sama menunjukkan tidak berbeda nyata berdasarkan uji DMRT pada taraf $\alpha=10 \%$. SR $=$ Survival rate (tingkat kelangsungan hidup); FCR $=$ Feed convertion ratio (rasio konversi pakan)

Tabel 6. Produksi dan nilai produksi padi dan ikan

\begin{tabular}{lcccc}
\hline \multirow{2}{*}{ Perlakuan } & \multicolumn{2}{c}{ Padi } & \multicolumn{2}{c}{ Ikan } \\
\cline { 2 - 5 } & $\begin{array}{c}\text { Produksi } \\
\left.\text { (ton ha })^{-1}\right)\end{array}$ & $\begin{array}{c}\text { Nilai produksi } \\
(\mathrm{Rp})\end{array}$ & $\begin{array}{c}\text { Produksi } \\
\left.\text { (ton ha }^{-1}\right)\end{array}$ & $\begin{array}{c}\text { Nilai produksi } \\
(\mathrm{Rp})\end{array}$ \\
\hline Monokultur padi 100\% pupuk anorganik & 5.12 & $30,464,000$ & - & - \\
Monokultur ikan & - & - & 0.52 & $20,920,000$ \\
Minapadi 100\% pupuk anorganik & 5.67 & $33,736,500$ & 0.46 & $18,520,000$ \\
Minapadi 60\% pupuk anorganik & 4.88 & $29,036,000$ & 0.48 & $19,160,000$ \\
Minapadi 20\% pupuk anorganik & 5.01 & $29,809,500$ & 0.41 & $16,360,000$ \\
\hline
\end{tabular}

Tabel 7. Usaha tani monokultur dan minapadi (penerimaan, biaya, keuntungan dan B/C rasio)

\begin{tabular}{lcrrc}
\hline Perlakuan & Penerimaan (Rp) & Biaya (Rp) & Keuntungan (Rp) & B/C \\
\hline Monokultur padi 100\% pupuk anorganik & $30,464,000$ & $13,595,000$ & $16,869,000$ & 1.2 \\
Monokultur ikan & $20,920,000$ & $9,918,750$ & $11,001,250$ & 1.1 \\
Minapadi 100\% pupuk anorganik & $52,256,500$ & $15,891,250$ & $36,365,250$ & 2.3 \\
Minapadi 60\% pupuk anorganik & $48,196,000$ & $14,218,750$ & $33,977,250$ & 2.4 \\
Minapadi 20\% pupuk anorganik & $46,169,500$ & $13,236,250$ & $32,933,250$ & 2.5 \\
\hline
\end{tabular}

keuntungan Rp 16,869,000. Minapadi dengan 100\% pupuk anorganik menghasilkan $\mathrm{B} / \mathrm{C}$ ratio 2.3 dan keuntungan Rp 36,365,250. Minapadi dengan 60\% pupuk anorganik menhasilkan B/C rasio 2.4 dan keuntungan Rp 33,977,250. Minapadi dengan 20\% pupuk anorganik menghasilkan B/C rasio 2.5 dan keuntungan $\mathrm{Rp} 32,933,250$. Monokultur ikan menghasilkan $\mathrm{B} / \mathrm{C}$ rasio sebesar 1.1 dan keuntungan $\mathrm{Rp}$ $11,001,250$.

Monokultur padi dan monokultur ikan pada mulanya membutuhkan biaya yang tidak sedikit, terutama kebutuhan pupuk baik pada padi ataupun kebutuhan pakan pada kolam budidaya ikan serta kebutuhan-kebutuhan lainnya. Oleh karena itu, secara ekonomis minapadi lebih menguntungkan dibandingkan monokultur, bahkan dapat mengurangi input pupuk anorganik dari luar sebanyak $80 \%$; perlakuan minapadi dengan $20 \%$ dosis pupuk anorganik menghasilkan
$\mathrm{B} / \mathrm{C}$ ratio dan keuntungan yang lebih tinggi daripada minapadi dengan $100 \%$ dosis pupuk anorganik. Menurut Syahputra et al. (2016), pada dasarnya analisis biaya dan pendapatan pada setiap sistem budidaya padi, minapadi, dan budidaya ikan itu menguntungkan serta berkontribusi terhadap pendapatan rumah tangga petani; sistem minapadi lebih menguntungkan dibandingkan dengan lainnya. Menurut Bosma et al. (2012), integrasi padi bersama ikan dapat memberikan petani pendapatan yang lebih tinggi dan meningkatkan produktivitas pertanian, serta dapat menjadi sebuah alat adaptasi perubahan iklim dalam konteks fisik, dan sosial ekonomi tertentu. Selain itu, integrasi antara tanaman dengan ikan mampu menyediakan pupuk organik internal dan mampu memanfaatkan lahan secara efisien dan produktif dibandingkan dengan monokultur (Suwarto et al., 2015). 


\section{KESIMPULAN}

Minapadi dapat mengurangi aplikasi pupuk anorganik melalui hubungan komplementer antara padi dan ikan. Pemberian pupuk anorganik $20 \%$ dosis acuan pada minapadi dengan ikan yang ditebar pada saat tanaman $90 \%$ bermalai menghasilkan produktivitas padi tidak berbeda nyata dengan pemberian pupuk anorganik $60 \%$ dan $100 \%$ dosis acuan pada minapadi dan $100 \%$ dosis acuan pada monokultur padi. Minapadi pada kondisi tanah awal dengan status hara nitrogen sedang, hara fosfor dan kalium sangat tinggi, dapat menghemat sebesar $80 \%$ pupuk anorganik sehingga meningkatkan efisiensi penggunaan pupuk anorganik. Kelangsungan hidup ikan dan bobot ikan pada minapadi tidak berbeda nyata dengan monokultur ikan.

\section{DAFTAR PUSTAKA}

Abdulrachman, S., M.J. Mejaya, N. Agustiani, I. Gunawan, P. Sasmita, A. Guswara. 2013. Panduan sistem tanam legowo. Suharna (Ed.). Badan Penelitian dan Pengembangan Pertanian, Sukamandi, ID.

Abu, R.L.A., B. Zainuddin, M. Usman. 2017. Respon pertumbuhan dan hasil tanaman padi (Oryza sativa L.) terhadap kebutuhan nitrogen menggunakan bagan warna daun. J. Agroland. 24:119-127.

[BB Padi] Balai Besar Penelitian Tanaman Padi. 2015. Pemupukan pada tanaman padi. http://bbpadi. litbang. pertanian.go.id/index.php/berita/info-teknologi/ content/226-pemupukan [28 Agustus 2017].

Bosma, R.H., D.K. Nhan, H.M.J. Udo, U. Kaymak. 2012. Factors affecting farmers' adoption of integrated ricefish farming systems in the Mekong delta, Vietnam. Aquaculture. 4:178-190.

Buresh, R.J. 2006. Site-specific nutrient management (SSNM) for rice. International Rice Research Institute, Metro Manila, PH.

Cahyaningrum, W., Widiatmaka, K. Soewardi. 2014. Arahan spasial pengembangan minapadi berbasis kesesuaian lahan dan analisis A'WOT di Kabupaten Cianjur, Jawa Barat. Majalah Ilmiah Globe. 15:77-88.

Cahyanti, W., V.A. Prakoso, O.Z. Arifin, I.I. Kusmini. 2014. Produksi ikan unggul di lahan minapadi secara intensif. Jurnal Sains Natural Universitas Nusa Bangsa. 4:26-33.

Effendie, M.I. 1979. Metoda Biologi Perikanan. Yayasan Dewi Sri, Bogor, ID.
Febrianti, H., K. Sukarti, C. A. Pebrianto. 2016. Pengaruh perbedaan sumber asam lemak pada pakan terhadap pertumbuhan ikan bawal bintang (Trachinotus blochii, Lecepede). J. Aquawarman. 2:24-33.

Fengbo, L., S. Zhiping, Q. Hangying, Z. Xiyue, X. Chunchun, W. Dianxin, F. Fuping, F. Jinfei, Z. Ning. 2019. Effect of rice-fish co-culture on oxygen consumption in in intensive aquaculture pond. Rice Sci. 26:50-59.

Hu, L., W. Ren, J. Tang, N. Li, J. Zhang, X. Chen. 2013. The productivity of traditional rice-fish co-culture can be increased without increasing nitrogen loss to the environment. Agric. Ecosys. Environ. 177:28-34.

Hu, L., J. Tang, J. Zhang, W. Ren, L. Guo, M. Halwart, K. Li, Z. Zhu, Y. Qian, M. Wu, X. Chen. 2015. Development of rice-fish system: today and tomorrow. Chin. J. Ecol. 23:268-275.

Kalsim, D.K., Yushar, Subari, M.D. Joubert, H.A. Sofiyuddin. 2007. Rancangan Operasional Irigasi untuk Pengembangan SRI. Paper disajikan dalam Seminar KNIICID. Bandung 24 November 2007.

Lazzari, R., B. Baldisserotto. 2008. Nitrogen and phosphorus waste in fish farming. B. Inst. Pesca. 34:591-600.

Noorhosseini-Niyaki, S.A., F. Bagherzadeh-Lakani. 2013. Ecological and biological effect of fish farming in rice fields. PGCP. 2:1-7.

Nurfaijah, B.I. Setiawan, C. Arif, S. Widodo. 2015. Sistem kontrol tinggi muka air untuk budidaya padi. Jurnal Irigasi. 10:97-110.

Oehme, M., M. Frei, M.A. Razzak, S. Dewan, K. Becker. 2007. Studies on nitrogen cycling under different nitrogen inputs in integrated rice-fish culture in Bangladesh. Nutr. Cycl. Agroecosyst. 79:181-191.

Patti, P.S., E. Kaya, C.H. Silahooy. 2013. Analisis status nitrogen tanah dalam kaitannya dengan serapan $\mathrm{N}$ oleh tanaman padi sawah di Desa Waimital, Kecamatan Kairatu, Kabupaten Seram Bagian Barat. Agrologia. 2:51-58.

Purwanto, E., A. Rauf, U. Made. 2017. Uji pola jajar legowo pada beberapa varietas padi sawah (Oryza sativa L.) budidaya SRI. E-J. Agrotekbis. 5:653-660.

Rana, S.S., P. Chopra. 2013. Integrated Farming System. Himachal Pradesh Agriculture University, Palampur, IN. 
Rauf, A.W., T. Syamsudin, S.R. Sihombing. 2000. Peranan pupuk anorganik NPK pada tanaman padi. Badan Penelitian dan Teknologi Pertanian, Jayapura, ID.

Sanderson, M.A., D. Archer, J. Hendrickson, S. Kronberg, M. Liebig, K. Nichols, M. Schmer, D. Tanaka, J. Aguilar. 2013. Diversification and ecosystem services for conservation agriculture: outcomes from pastures and integrated crop-livestock systems. Renewable Agric. Food Syst. 28:129-144.

Senoaji, W., R.H. Pratana. 2013. Interaksi nitrogen dengan insidensi penyakit tungro dan pengendaliannya secara terpadu pada tanaman padi. Iptek Tanaman Pangan. 8:80-89.

Siikavuopio, S.I., R. Knudsen, P.A. Amundsen, B.S. Saether, P. James. 2012. Effect of high temperature on growth of European whitefish (Coregonus lavaretus L.) Aquacult. Res. 44:8-12

Siregar, A., I. Marzuki. 2011. Efisiensi pemupukan urea terhadap serapan $\mathrm{N}$ dan peningkatan produksi padi sawah (Oryza sativa L.). J. Budidaya Pertanian. 7:107-176.

Sudiarta, I.M., E. Syamun, R. Syamsuddin. 2016. Pertumbuhan dan produksi tanaman padi serta produksi ikan nila pada sistem tanam jajar legowo. J. Sains dan Teknologi 16:70-80.

Sunarno, 1991. Pemeliharaan ikan jelawat (Leptobarsa hoeveni) dengan frekuensi pemberian pakan yang berbeda. Bul. Perik. Darat 10:76-80.

Suwarto, A.T. Aryanto, I. Effendi. 2015. Perancangan model pertanian terpadu tanaman-ternak dan tanaman-ikan di perkampungan teknologi Telo, Riau. J. Agron. Indonesia 43:168-177.
Syahputra, B.S.A., Jambari, H. Ali. 2016. Comparison finansial analyses among rice farming, rice-fish farming and fish only on a smallholders' community in Teluk Intan, Perak, Malaysia. World J. Fish Marine Sci. 8:170-176.

Tando, E. 2018. Review: upaya efisiensi dan peningkatan ketersediaan nitrogen dalam tanah serta serapan nitrogen pada tanaman padi sawah (Oryza sativa L.) Buana Sains 18:171-180.

Triadiati, A.P. Akbar, A. Sarlan. 2012. Pertumbuhan dan efisiensi penggunaan nitrogen pada padi (Oryza Sativa L.) dengan pemberian pupuk urea yang berbeda. Bul. Anatomi Fisiol. 20:1-14.

Tsuruta, T, M. Yamaguchi, S. Abe, K. Iguchi. 2011. Effect of fish in rice-fish culture on the rice yield. Fish. Sci. 77:95-106.

Xiang, J., V.R. Haden, S. Peng, B.A.M Bouman, J.L. Huang, K.H. Cui, R.M. Visperas, D. Zhu, Y. Zhang, H. Chen. 2013. Effect of deep placement of nitrogen fertilizer on growth, yield, and nitrogen uptake of aerobic rice. AJCS. 7:870-877.

Vromant, N., N.T.H. Chau. 2005. Overall effect of rice biomassa and fish on the aquatic ecology of experimental rice plots. Agric. Ecosyst. Environ. 111:153-165.

Xie, J., L. Hu, J. Tang, X. Wu, N. Li, Y. Yuan, H. Yang, J. Zhang, S. Luo, X. Chen. 2011. Ecological mechanism underlying the sustainability of the agriculture heritage rice-fish coculture system. PNAS. 108: E1381-E1387. 